\title{
Kan inhalatieanesthesie midazolam vervangen bij ARDS-patiënten op de ic?
}

\section{CAASUS}

Op de intensive care (ic) wordt meestal intraveneus midazolam toegediend om ARDS-patiënten te sederen. Midazolam is voor ic-patiënten echter geen ideaal sedatiemiddel: bij lever- en nierfunctiestoornissen duurt het langer voordat het is uitgewerkt en het geeft gewenning en ontwenning. Inhalatieanesthetica kunnen een alternatief zijn. Uit een recente metaanalyse blijkt dat inhalatieanesthetica, vergeleken met midazolam, zorgen voor een kortere tijd tot detubatie en geen nadelige effecten hebben op sterfte of opnameduur. ${ }^{1}$ Deze studie keek niet specifiek naar ic-patiënten met ARDS of naar relevante uitkomstmaten voor deze groep. Het is de vraag wat de effecten van sedatie met inhalatieanesthetica zijn op longfunctie, hemodynamiek en sedatiestabiliteit bij ARDS-patiënten.

tekst Irma van den Berg*

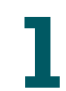

\section{Formuleer je vraag}

(PICO: $P=$ patiënt of probleem, $I=$ interventie, $C=$ vergelijking, $\mathrm{O}=$ uitkomst)

$\mathrm{P}$ Volwassen ic-patiënten met ARDS

I Inhalatieanesthesie

C Midazolamsedatie (intraveneus)

O Longfunctie, hemodynamiek en sedatiestabiliteit

\section{2}

\section{Zoekstrategie}

Gezocht in PubMed met onderstaande zoektermen, gecombineerd met de boolean operators AND en OR: respi- ratory distress syndrome, adult, acute respiratory distress syndrome, ARDS, anesthetics, inhalation, inhalation, volatile, anesthe ${ }^{*}$, anaesthe ${ }^{*}$, sedat*, desflurane, isoflurane, sevoflurane, anesthetics, intravenous, $I V$, TIVA, midazolam, dormicum. Dat leverde 2 geschikte onderzoeken op: een RCT en een retrospectief cohortonderzoek. ${ }^{2,3}$ De kwaliteit van de onderzoeken is beoordeeld met Cochrane Netherlands.

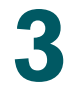

\section{Beoordeling resultaten}

In de RCT van Jabaudon et al. ${ }^{2}$ werden 50 ic-patiënten met matige tot ernstige ARDS gesedeerd en volledig beademd. Na randomisatie kregen 25 patiënten inhalatieanesthesie (sevofluraan) toegediend door continue verdamping om diepe sedatie te bereiken. De andere 25 patiënten kregen intraveneus midazolam. Na 2 dagen werd de longfunctie bepaald door middel van de $\mathrm{PaO}_{2} / \mathrm{FiO}_{2}$ ratio. Deze was beter in de inhalatiegroep dan in de intraveneuze groep (205 vs. $166 \mathrm{mmHg}$ ). De onderzoekers vonden na 2 dagen geen verschil tussen beide groepen in hemodynamiek: gemiddelde bloeddruk, hartfrequentie en dosering van noradrenaline waren gelijk. In dit onderzoek is niet naar de sedatiestabiliteit gekeken.

Het retrospectieve onderzoek van Meiser et al. ${ }^{3}$ heeft ziekenhuisdata van 38 ic-patiënten met ernstige ARDS onderzocht. Bij 19 patiënten was isofluraan toegediend 


\section{WAT IS ARDS OOK ALWEER?}

Acute respiratory distress syndrome (ARDS), ook wel shocklong genoemd, is een hyperactieve ontstekingsreactie waarbij een enorme hoeveelheid ontstekingsstofjes en ontstekingscellen vrijkomt. Hierdoor ontstaat lekkage van de longcapillairen en lekt er eiwitrijk vocht uit de capillairen in de alveoli. Dit beperkt de zuurstofoverdracht naar het bloed en de patiënt wordt kritisch ziek, met ernstige dyspneu en hypoxemie ondanks zuurstoftoediening. De behandeling bestaat voornamelijk uit vochtmanagementstrategieën en mechanische beademing, om zo voldoende zuurstof in het bloed te garanderen zonder de longen verder te beschadigen. Patiënten worden tijdens de mechanische beademing gesedeerd. De ernstig verstoorde gaswisseling kan leiden tot multi-orgaanfalen en daardoor overlijden. ${ }^{4}$

door verdamping en bij 19 patiënten midazolam/propofol intraveneus voor diepe sedatie. De metingen van de eerste 24 uur zijn geanalyseerd. Na 24 uur was de $\mathrm{PaO}_{2} / \mathrm{FiO}_{2}$-ratio in zowel de inhalatiegroep als intraveneuze groep gestegen (195 vs. $199 \mathrm{mmHg}$ ). Wel bleek dat $90 \%$ van de patiënten in de inhalatiegroep na 24 uur spontaan kon ademhalen te- genover 16\% in de andere groep. De hemodynamiek verschilde niet tussen beide groepen. De patiënten met inhalatieanesthesie bereikten na 24 uur een diepere sedatie dan de intraveneuze groep. Wel waren in de inhalatiegroep iets meer doseringsaanpassingen nodig dan in de intraveneuze groep, maar dit verschil was niet statistisch significant.

Minpunt is dat beide onderzoeken slechts kleine aantallen patiënten bevatten. Ook was blindering van patiënten en behandelaren niet mogelijk vanwege de apparatuur. Het onderzoek van Meiser et al. was retrospectief en patiënten waren niet gerandomiseerd. De resultaten kunnen hierbij vertekend zijn doordat de twee groepen mogelijk van elkaar verschilden in ziektekarakteristieken.

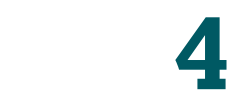

\section{Conclusie}

Inhalatieanesthesie leidt tot een betere longfunctie bij AR-

nurSIng/congressen

\title{
MASTERCLASS EBP
}

\begin{abstract}
Tijdens de Masterclass EBP (27 oktober, Ede) gaan we in op EBP en klinisch redeneren, het implementeren van EBP in je organisatie, en EBP en leiderschap. De masterclass is gericht op EBP-gebruikers en -experts. Zie www.masterclassebp.nl voor alle informatie.
\end{abstract}

DS-patiënten dan intraveneuze sedatie. Daarbij wordt met inhalatieanesthesie een betere stabiliteit in sedatiediepte bereikt dan met intraveneuze sedatie, zonder dat het effect heeft op de hemodynamiek.

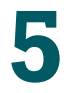

\section{Evaluatie}

Inhalatiesedatie kan een alternatief zijn voor intraveneuze sedatie van ic-patiënten met ARDS. Verpleegkundigen op ic-afdelingen kunnen daarmee gemakkelijker het gewenste sedatieniveau bereiken bij de patiënt en 'daily wake-up calls' uitvoeren, om

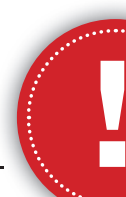

zo meer comfort te bieden in een kritieke periode. Veilige inhalatiesedatie met sevofluraan/isofluraan is mogelijk met het AnaConDa-filter (Anaesthetic Conserving Device). Deze vervangt het HME-filter. Daarnaast moet ook een actief koolstoffilter worden aangeschaft.

Het is nog niet bekend of de beschreven effecten ook bereikt worden bij covid19-patiënten op de ic, daarvoor is een gerandomiseerde studie nodig.

* Irma van den Berg is ic-verpleegkundige en werkte tijdens het schrijven van deze CAT in OLVG, locatie Oost te Amsterdam. Nu is ze ic-verpleegkundige in het Zaans Medisch Centrum in Zaandam. Contact: irmvdberg@gmail.com. Dit artikel is een ingekorte versie van het origineel.

\section{Ja, inhalatiesedatie kan een alternatief zijn voor intraveneuze sedatie van ic-patiënten met ARDS, al zijn de beschreven onderzoeksgroepen klein}

\section{Noten}

1 Jerath A, et al. Safety and Efficacy of Volatile Anesthetic Agents Compared With Standard Intravenous Midazolam/Propofol Sedation in Ventilated Critical Care Patients: A
Meta-analysis and Systematic Review of Prospective Trials. Anesth Analg, 2017; 124: 11901199.

2 Jabaudon M, et al. Sevoflurane for Sedation in Acute Res- piratory Distress Syndrome. A Randomized Controlled Pilot Study. Am J Respir Crit Care Med, 2017; 195: 792-800

3 Meiser A et al. Inhalation

Sedation in Subjects With
ARDS Undergoing Continuous Lateral Rotational Therapy. Respir Care, 2018; 63: 441-447.

4 Klinisch redeneren COVID-19, video Amstel Academie VUmc. 